\title{
Características morfológicas, melhoramento genético e densidade de plantio das culturas do sorgo e do milho: uma revisão
}

Morphological characteristics, genetic improvement and planting density of sorghum and corn crops: a review

Características morfológicas, mejora genética y densidad de plantación de los cultivos de sorgo y maíz: una revisión

Davi Francisco da Silva

ORCID: https://orcid.org/0000-0002-9518-8573 Universidade Federal de Alagoas, Brasil

E-mail: davifranciscodasilva01@ gmail.com

Pedro Henrique de Melo Garcia ORCID: https://orcid.org/0000-0001-8210-3166 Universidade Estadual Paulista, Brasil E-mail: pedrogarcia.ufal@gmail.com

Girlene Cordeiro de Lima Santos ORCID: https://orcid.org/0000-0002-6979-6321 Universidade Federal da Paraíba, Brasil E-mail: girlenecordeiross@gmail.com

Iasmin Myrele Santos Calaça de Farias ORCID: https://orcid.org/0000-0001-6605-3824 Universidade Estadual Paulista, Brasil E-mail: iasminmyrele@gmail.com

Guilherme Vinicius Gonçalves de Pádua ORCID: https://orcid.org/0000-0001-6616-724X Universidade Federal da Paraíba, Brasil E-mail: guilhermegpadua@yahoo.com.br

Pedro Henrique Borba Pereira ORCID: https://orcid.org/0000-0002-3999-4036 Universidade Federal do Agreste de Pernambuco E-mail: pedro.borba.pereira@gmail.com

Francisco Edson da Silva

ORCID: https://orcid.org/0000-0002-6748-2572 Universidade Federal da Paraíba, Brasil E-mail: frc@gmail.com

Regiane Farias Batista

ORCID: https://orcid.org/0000-0002-3728-4006 Universidade Federal da Paraíba, Brasil

E-mail: regiane.2594@gmail.com

Severino Gonzaga Neto

ORCID: https://orcid.org/0000-0003-4220-4071 Universidade Federal da Paraíba, Brasil

E-mail: sgonzaganeto@gmail.com

Ana Maria Duarte Cabral

ORCID: https://orcid.org/0000-0002-6101-1104

Universidade Federal Rural de Pernambuco, Brasil

E-mail: amdcabral@gmail.com

\section{Resumo}

Nesse estudo, objetivou-se realizar uma breve revisão sobre características morfológicas, melhoramento genético e densidade de plantio das culturas do sorgo (Sorghum bicolor L.) e do milho (Zea mays L.). A busca da literatura incluída no estudo foi conduzida por meio de uma pesquisa eletrônica nas bases de dados Google Scholar, Scientific Electronic Library Online (SciELO), na web e em sites da Empresa Brasileira de Pesquisa Agropecuária EMBRAPA. Como critério de inclusão, se considerou bibliografias que tratassem de temas relacionados a morfologia, genética e densidades de plantio do milho e do sorgo. Os critérios de exclusão das bibliografias foram: estudos fora do objetivo do estudo e que não contemplaram o período e idioma estabelecido da pesquisa. De modo geral, o milho e o sorgo são gramíneas que contribuem diretamente com a cadeia produtiva e com o agronegócio, em decorrência da 
sua importância nutricional em sistemas de produção animal. As suas caraterísticas botânicas, morfológicas e fenológicas, permitem que essas culturas apresentem boa produtividade e adaptabilidade em diferentes regiões do Brasil (Sul, Região Central e Nordeste). A capacidade de adaptação do milho e do sorgo às distintas condições edafoclimáticas, dependem do potencial genético da semente e do sistema de plantio empregado, bem como, da competência do tipo de genótipo em suportar até certo ponto altas densidades populacionais. Sugere-se a condução de estudos que avaliem individualmente os atributos morfológicos e fenológicos de distintas variedades do milho e do sorgo e suas habilidades de adaptação e produção em diferentes densidades de plantio.

Palavras-chave: Sorghum bicolor L.; Zea mays L.; Arranjo espacial do cultivo.

\begin{abstract}
In this study, the objective was to perform a brief review on morphological characteristics, genetic improvement and planting density of sorghum (Sorghum bicolor L.) and corn (Zea mays L.) crops. The search for the literature included in the study was conducted by means of an electronic search in the Google Scholar and Scientific Electronic Library Online (SciELO) databases, on the web and on the Empresa Brasileira de Pesquisa Agropecuária - EMBRAPA websites. As inclusion criteria, we considered bibliographies dealing with topics related to morphology, genetics and planting densities of corn and sorghum. The exclusion criteria for the bibliographies were: studies outside the study's objective and that did not contemplate the established period and language of the research. In general, corn and sorghum are grasses that directly contribute to the production chain and agribusiness due to their nutritional importance in animal production systems. Their botanical, morphological and phenological characteristics allow these crops to show good productivity and adaptability in different regions of Brazil (South, Central and Northeast). The ability of corn and sorghum to adapt to different edaphoclimatic conditions depends on the genetic potential of the seed and the planting system used, as well as the competence of the genotype type to withstand high population densities to some extent. We suggest conducting studies to individually evaluate the morphological and phenological attributes of different varieties of corn and sorghum and their adaptation and production abilities at different planting densities.
\end{abstract}

Keywords: Sorghum bicolor L.; Zea mays L.; Crop spatial arrangement.

\title{
Resumen
}

En este estudio, se pretende realizar una breve revisión sobre las características morfológicas, la mejora genética y la densidad de plantación de los cultivos de sorgo (Sorghum bicolor L.) y maíz (Zea mays L.). La búsqueda de la literatura incluida en el estudio se realizó mediante una búsqueda electrónica en las bases de datos Google Scholar, Scientific Electronic Library Online (SciELO), en la web y en los sitios de la Corporación Brasileña de Investigación Agropecuaria - EMBRAPA. El criterio de inclusión fue el de las bibliografías que trataban temas relacionados con la morfología, la genética y las densidades de plantación del maíz y el sorgo. Los criterios de exclusión de las bibliografías fueron: estudios fuera del objetivo del estudio y que no incluyeran el período y el idioma establecidos para la investigación. En general, el maíz y el sorgo son gramíneas que contribuyen directamente a la cadena de producción y a la agroindustria debido a su importancia nutricional en los sistemas de producción animal. Sus características botánicas, morfológicas y fenológicas permiten que estos cultivos muestren una buena productividad y adaptabilidad en diferentes regiones de Brasil (regiones Sur, Centro y Nordeste). La capacidad de adaptación del maíz y el sorgo a las diferentes condiciones edafoclimáticas depende del potencial genético de la semilla y del sistema de plantación utilizado, así como de la competencia del tipo de genotipo para soportar hasta cierto punto altas densidades de población. Se sugiere realizar estudios para evaluar individualmente los atributos morfológicos y fenológicos de las diferentes variedades de maíz y sorgo y su capacidad de adaptación y producción a diferentes densidades de plantación.

Palabras clave: Sorghum bicolor L.; Zea mays L.; Disposición espacial del cultivo.

\section{Introdução}

O milho (Zea mays L.), espécie nativa das américas e o sorgo (Sorghum bicolor L.), originário do Noroeste da África, são culturas que se destacam em meio ao setor agropecuário (Toledo, 1980; Coelho, 2010), uma vez que, possuem um importante papel na alimentação animal. Essas gramíneas, além de utilizadas de diferentes formas, tais como, pastejo, corte verde e silagem, são culturas notáveis nos atributos de produtividade, adaptação e digestibilidade.

O milho apresenta características interessantes, por exemplo, suas raízes, tipo escoras, favorecem a fixação do caule da planta para uma melhor absorção de sais minerais (Fornasieri Filho, 2007), o endosperma do grão, é uma importante fonte de carboidratos e proteínas (Paes, 2008). Todavia, o período vegetativo e a floração do milho podem variar conforme fatores climáticos (Barbano et al., 2001). O sorgo, é uma forrageira potencialmente resistente à desidratação, graças ao seu sistema 
radicular fibroso e as características de uma planta xerófita, que viabilizam a redução de perda de água para o ambiente (Fontes \& Moura Filho, 1979). No Brasil, por exemplo, tanto no Sul, como na região Central e em condições do semiárido do Nordeste, o sorgo tem apresentado uma boa adaptabilidade, apontando seu alto potencial produtivo em regiões distintas do país (Neumann et al., 2005; Pereira et al., 2011; Santos et al., 2020).

Com a necessidade de cultivares com maior potencial produtivo e o progresso no melhoramento genético, várias variedades dessas culturas são propagadas no mercado (Argenta et al., 2001; Perazzo et al., 2013). Contudo, além do potencial genético da semente da cultivar e da sua capacidade de adaptação a condições edafoclimáticas, o resultado de produção de uma lavoura também depende do sistema de plantio empregado na plantação (Cruz et al., 2012), visto que o arranjo espacial utilizado depende do poder de competição da cultura, ou seja, da sua capacidade de suportar até certo ponto altas densidades populacionais. Em outras palavras, a capacidade produtiva de uma cultivar submetida a distintas densidades de plantio, depende do seu genótipo, uma vez que, as variedades de cultivares respondem de maneiras diferentes ao manejo utilizado (Alvarez et al., 2006; Silva et al., 2006). Desse modo, para que o potencial de produção máxima de um cultivo seja alcançado, é fundamental avaliar as características morfológicas, genéticas e o arranjo espacial empregado (Santos et al., 2005; Cruz et al., 2012; Garcia et al., 2020). Diante do exposto, objetivou-se realizar uma revisão sobre características morfológicas, melhoramento genético e densidade de plantio das culturas do sorgo e do milho.

\section{Metodologia}

O presente estudo, trata-se de uma revisão exploratória de caráter qualitativo e informativo, sobre as características morfológicas, melhoramento genético e densidade de plantio das culturas do sorgo e do milho. Estudos baseados em informações qualitativas contribuem expressivamente para a propagação de evidências científicas sobre o objeto de estudo (Pereira et al., 2018).

A busca da literatura incluída no estudo, foi conduzida por meio de uma pesquisa eletrônica nas bases de dados Google Scholar e Scientific Electronic Library Online (SciELO). Para uma melhor acuracidade da busca, também se utilizou dados e/ou informações de livros e publicações cientificas disponíveis na web e em sites da Empresa Brasileira de Pesquisa Agropecuária - EMBRAPA.

Como critério de inclusão, foram consideradas bibliografias que tratassem de temas relacionados a morfologia, genética e densidades de plantio do milho e sorgo utilizados na alimentação animal, que estivessem no período de 1979 a 2020

Foram consideradas como critérios de exclusão as bibliografias que não atenderam ao objetivo do estudo, não estavam dentro da margem do período descrito para a realização da pesquisa e não estavam dentro do idioma determinado.

Para a análise e interpretação dos resultados foi realizada uma leitura analítica com a finalidade de ordenar e sumarizar as informações contidas nas fontes, de forma que estas possibilitassem a obtenção de respostas ao problema da pesquisa.

A coleta de dados seguiu a seguinte premissa: a) Leitura exploratória de todo o material selecionado (leitura rápida que tinha como objetivo verificar se a obra consultada apresentava interesse para o trabalho); b) Leitura seletiva (leitura mais aprofundada das partes que realmente interessavam para o estudo); c) Registro das informações por meio de fichamento (autores, ano, método, resultados e conclusão).

\section{Revisão de Literatura}

\section{Botânica, características morfológicas e fenológicas do milho e do sorgo}

Conforme sua botânica, o milho pertence a ordem Poales, família Poaceae, subfamília Panicoideae, tribu Maydeae, 
gênero Zea, espécie Zea mays (Queiroz, 2009), sendo uma das poucas espécies econômicas nativas das Américas. É também uma planta herbácea, anual e com ciclo completo de quatro a cinco meses. Além disso, o milho é uma planta monóica com flores femininas nas axilas das folhas (espigas) e com flores masculinas na extremidade superior (panículas) (Toledo, 1980).

Na Tabela 1, são mostrados os estádios vegetativos (V) e reprodutivos (R) do milho. As subdivisões dos estádios vegetativos são designadas numericamente como V1, V2, V3 até o V (n), que representa a última folha emitida antes do pendoamento (VT). O primeiro e o último estádio V, são representados por VE (emergência) e VT (pendoamento), respectivamente (Magalhães \& Durães, 2006). As etapas dos estádios reprodutivos são divididas em: florescimento (R1), grão leitoso (R2), grão pastoso (R3), grão farináceo - duro (R4) e maturidade fisiológica (R6), respectivamente.

Tabela 1 - Estádios vegetativos e reprodutivos de uma planta de milho.

\begin{tabular}{ll}
\hline Estádios Vegetativos & Estádios Reprodutivos \\
\hline VE - Emergência & R1 - Florescimento \\
V1 - Primeira folha & R2 - Grão leitoso \\
V2 - Segunda folha & R3 - Grão pastoso \\
V3 - Terceira folha & R4 - Grão farináceo - duro \\
V6 - Sexta folha & R6 - Maturidade fisiológica \\
V9 - Nona folha & \\
V12 - Décima segunda folha & \\
V15 - Décima quinta folha & \\
V18 - Décima oitava folha & \\
VT - Pendoamento &
\end{tabular}

Ritchie, Hanway e Benson (2003).

O milho, possui caule do tipo colmo, formado por nós e entrenós. Na parte superior desse sistema caulinar, as folhas encontram-se distribuídas de forma alternada de um lado ao outro no diâmetro inverso do caule. Constituído por limbo foliar largo, comprido e liso em sua maioria, gerando ângulo de $90^{\circ}$ com o caule por uma resistente nervura principal (Morais, 2012). Apresenta sistema radicular próprio das gramíneas, do tipo fasciculado ou em "cabeleira", atingindo uma profundidade de 1,5 a 3,0 m de comprimento, localizado nas camadas mais superficiais aos $0,30 \mathrm{~m}$, o que explica a pouca tolerância à deficiência hídrica; e raízes tipo escoras, conhecidas como adventícias ao qual auxiliam na fixação do caule da planta ajudando na absorção de sais minerais em solução (Fornasieri Filho, 2007). O período vegetativo depende dos fatores climáticos, onde o florescimento acontece em média de 5 a 12 semanas após a semeadura, podendo chegar até 10 meses. Em locais de clima temperado nos dias longos o florescimento acontece mais tardiamente (Barbano et al., 2001).

A fertilização do óvulo do milho dentro do ovário acontece de 12 a 36 horas após a polinização. O desenvolvimento do grão finaliza-se em média 60 dias após a fertilização, em que, ocorre um aumento de volume do ovário para o grão cerca de 1400 vezes. O grão do milho é fruto de uma semente, típica das gramíneas. Dentro do grão se encontra o endosperma e o embrião. O endosperma é responsável por cerca de $85 \%$ da massa do grão, o embrião corresponde a cerca de $10 \%$ e o pericarpo com 5\% (Bresolin \& Pons, 1983). Grande parte do endosperma é principalmente constituído de amido, 86 a $89 \%$ de carboidrato e $75 \%$ de proteína. Além disso, nas células do endosperma, o amido está no formato de grânulos, composto por dois polissacarídeos de glucose (75\% de amilopectina e 25\% de amilose) (Paes, 2008). 
A cultura do sorgo é originária do Noroeste da África, sendo encontrada na maioria dos genótipos de espécies silvestres e/ou cultivadas. A dispersão da cultura deu-se início através das rotas de comércio, com isso houve a expansão para o Oriente Médio, China, Estados Unidos, América Latina e Austrália (Coelho, 2010).

A planta do sorgo pertence à família Poaceae, gênero Sorghum, e a espécie cultivada é Sorghum bicolor (L.) Moench. É uma forrageira de mecanismo fotossintético C4 o que demonstra enorme vantagem fotossintética (Andrade Neto et al., 2010). Além disso, é uma cultura que no meio agropecuário brasileiro ganha destaque a cada dia, por ser uma gramínea energética, de elevada digestibilidade, produtividade e adaptação aos mais diversos ambientes, se sobressaindo quando comparado com outras espécies, sendo utilizada para diversos fins, como corte verde, silagem, pastejo, rações para animais e para o consumo humano.

O sorgo possui os seguintes atributos morfológicos: colmo ereto, com suporte em um sistema radicular muito resistente com raízes seminais e adventícias, possuindo também folhas alternadas compostas por bainha e lâmina foliar com origem nos nós individuais, onde o número de folhas varia de 7 a 30. A inflorescência é chamada de panícula, ao qual possui eixo central, onde dá origem as ramificações primárias, secundárias e terciárias, nas ramificações finais localizam-se os racemos ou espiguetas, podendo ser a panícula compactada ou aberta (Santos et al., 2005).

A diferenciação floral no sorgo incide de 30 a 40 dias após a germinação e depois de 10 dias acontece o emborrachamento. O início do florescimento ocorre nas espiguetas sésseis do ápice para a base da panícula a cerca de quatro a seis dias, onde os grãos de pólen mantêm-se variável em média de três a cinco horas, onde os estigmas ficam disponíveis para o cruzamento durante uma semana ou até mais (Magalhães et al., 2010).

O desenvolvimento do sorgo corresponde a três estágios de crescimento (EC). EC1, ocorre desde a germinação até diferenciação da panícula. Nesta fase, é importantíssimo que a germinação se estabeleça com rapidez, devido a plântula ser bastante susceptível a estresses abióticos. Na próxima etapa (EC2), que se inicia da panícula até o florescimento, o fotoperíodo é de suma importância para sua transição, uma vez que, o sorgo é uma planta de dias curtos, e o rendimento de grãos é sustentado pelo bom crescimento de área foliar, além do eficiente sistema radicular e acúmulo de matéria seca. A última fase (EC3), que se inicia na floração e termina na maturação fisiológica dos grãos, os fatores para um bom rendimento da cultura está relacionado ao enchimento dos grãos (Magalhães, Durães, \& Rodrigues, 2009).

O sorgo necessita de menor quantidade de água para desenvolver suas funções fisiológicas, quando comparado com outros cereais. Para motivos de comparação, a exemplo de milho e trigo, essas espécies necessitam de 370 a $500 \mathrm{~kg}$ de água, respectivamente, para a produção de $1 \mathrm{~kg}$ de matéria seca, onde o sorgo necessita de apenas $330 \mathrm{~kg}$ de água (Magalhães et al., 2010).

De acordo com Fontes e Moura Filho (1979), o sorgo é uma forrageira bastante resistente à desidratação, graças ao seu sistema radicular fibroso e com grande extensão, que pode chegar a $1,5 \mathrm{~m}$ de profundidade, cerca de $50 \%$ menor que o do milho, com o ritmo de transpiração efetivo e com perfil foliar de planta xerófita, como a serosidade e a ausência de pilosidade, que permite a redução de perda de água pela planta.

Segundo Neumann et al. (2005), o sorgo no Brasil tem boa adaptabilidade em várias regiões, com plantio de verão, no Sul e na região Central; e com plantios de inverno a verão, no Nordeste, em condições de semiárido e elevada temperatura, e precipitação inferior a $600 \mathrm{~mm}$ anuais. O sorgo é uma planta de alta adaptabilidade, o que acarreta em um grande potencial para o plantio em regiões distintas do país (Pereira et al., 2011). O sorgo Sudão IPA 4202, por exemplo, em ambiente semiárido do Brasil, suporta diferentes regimes hídricos de água salina, e ainda assim, com quantidade de biomassa interessante para produção de forragem (Santos et al., 2020).

Diversas variedades de sorgo são lançadas no mercado, mas ainda é necessário que haja mais estudos que caracterizem e originem recomendações para melhor utilização, especificando tipos de sistemas e as melhores regiões para o 
uso de uma determinada cultivar (Perazzo et al., 2013).

\section{Importância do melhoramento genético do milho e do sorgo}

O constante progresso no melhoramento genético do milho, tem ocasionado o desenvolvimento e comercialização de cultivares com maior potencial produtivo, de ciclo variados, arquitetura mais ereta e porte baixo. Essas variedades possuem maior resistência ao acamamento e quebramento de plantas, facilitando a sucessão com outras culturas e mecanização, permanecendo pouco tempo sujeitos as condições adversas do campo. Todas essas características, permitem o alcance de melhores lucros na produção (Argenta et al., 2001).

Para o primeiro passo na produção de uma cultura é necessário realizar a escolha da semente. $\mathrm{O}$ resultado de produção de uma lavoura de milho é consequência do potencial genético da semente e das condições edafoclimáticas do local de plantio, além do manejo da plantação. De maneira geral, a cultivar é responsável por 50\% do rendimento final. No entanto, a escolha adequada da semente pode ser o motivo do sucesso ou não da lavoura. Verifica-se que o aumento do rendimento do milho nos principais locais de produção no Brasil desde metade do século XX, é semelhante ao modelo empregado pelos Estados Unidos, com o uso de sementes híbridas com elevado potencial de rendimento (melhoramento genético), maior utilização de fertilizantes e defensivos, alta densidade de semeadura, uso de tratores e implementos agrícolas eficientes e o uso do sistema de plantio direto na palha (Cruz et al., 2012).

O uso conjunto de variedades melhoradas, além de insumos e técnicas de cultivo adequados fez com que o rendimento das lavouras elevasse progressivamente. A grande seleção, com base no porte de plantas, em decorrência da preferência por plantas de baixa arquitetura, baixa inserção da $1^{\mathrm{a}}$ espiga, grande quantidade de grãos e elevada quantidade de matéria seca no colmo, gerou plantas mais eficientes, com elevadas produções, baixo percentual de tombamento e facilidade na colheita mecanizada (Cruz \& Pereira Filho, 2008).

Como origem o Noroeste Africano, o sorgo, cultivado nesta região do mundo, possui grande diversidade em características silvestres, uma vez que, possivelmente a domesticação dessa gramínea começou na Etiópia, por seleção das espécies silvestres (Sorghum arundinaceum) e (Sorghum verticilliflorum) há cerca de 7.000 anos (Maxiagro, 2010).

$\mathrm{O}$ fato de a espécie ter se originado no continente africano, explica sua tolerância a falta d'água, além disso o continente possui inúmeras áreas com elevadas temperaturas e restrição hídrica, possivelmente ocorrendo seleção natural, ocasionando a adaptação dos indivíduos a esse tipo de condição (Durães, 2014).

A coleção mundial de sorgo é cerca de 30.000 entradas, além de existirem milhares de outras linhagens no mundo em programas de melhoramento. Trata-se de uma cultura basicamente de espécie de autofecundação, com apenas uma pequena quantidade de intercruzamento (Schaffert, 2016).

O sorgo forrageiro aparece com inúmeros progressos no melhoramento genético, sendo uma cultura com fácil manuseio e de elevada produtividade, produção de biomassa e produto de excelente qualidade nutricional e de baixo custo para a produção animal (Embrapa, 2010).

Em nosso país a (Embrapa Milho e Sorgo), vem desenvolvendo pesquisas com o objetivo de empregar, adaptar e favorecer o desenvolvimento de cultivares, principalmente do sorgo forrageiro granífero e sacarino com alto rendimento e tolerância a condições de estresses climáticos. Os estudos têm possibilitado a obtenção e o lançamento de variedades com maior valor agregado, que possibilita uma melhoria no desempenho da cultura nas condições naturais das mais diversas regiões produtoras (Embrapa, 2010).

O melhoramento genético do sorgo pode ser realizado de acordo com a metodologia utilizada para plantas autógamas, conduzida a partir de uma população de cruzamento bi parental executado manualmente (Santos et al., 2005). 


\section{Importância da densidade de plantio do milho e sorgo}

O potencial produtivo de forrageiras como o milho e sorgo pode ser explorado pelo implemento criterioso de aspectos técnicos, como a escolha da cultivar, que se adapte às condições de cultivo, uso de espaçamento e manejo correto. Um dos fatores para a baixa produtividade da cultura e principalmente no Nordeste, é o uso de espaçamentos entre linhas inadequados. Com isso, o estudo da adaptação de cultivares, em distintos espaçamentos é considerado um fator importante para o bom desempenho produtivo dessas culturas (Viola, 1980).

Tradicionalmente, culturas como milho são plantadas nas grandes áreas produtoras com espaçamentos entre linhas de 0,80 e 0,90 m, favorecendo o adequado funcionamento das máquinas e implementos tradicionais, semeadura, tratos culturais e colheita (Mattoso et al., 2006).

Segundo Dourado Neto (1999), a maximização da produção das culturas vai depender da população utilizada, que pode variar de acordo com a capacidade de suporte do meio, sistema produtivo empregado, índice de duração da área foliar, época da semeadura e da correta distribuição espacial de plantas na área, que deverá ficar em harmonia com as características dos genótipos.

Para obter melhores resultados na produção forrageira, é muito importante a realização de técnicas apropriadas, entre elas, a utilização de genótipos produtivos e com boa adaptabilidade, manejo cultural competente, sobretudo um bom arranjo espacial entre linhas (Lima et al., 2016).

De acordo com Fornasieri Filho (1992), o índice produtivo individual por planta é máximo em baixa densidade (espaçamentos amplos), no entanto, o rendimento por área torna-se pequeno. No caso do milho, o tamanho das espigas aumenta se o milho prolífico tende a produzir mais que a espiga, nesse caso, o colmo fica rígido e forte dificultando a colheita mecanizada. Já com a redução do espaçamento entre linhas, acontece o aumento da densidade e da população de plantas, acarretando em um maior rendimento de planta por área (Fornasieri Filho, 1992).

No entanto, a escolha da densidade ideal de semeadura e melhor arranjo de plantas na área, está também relacionado aos índices produtivos da cultura do sorgo. Conforme Baumhardt e Howell (2006), a densidade de semeadura de sorgo, sofre variação em função do ciclo da cultivar e de condições de umidade da região. Contudo, os menores espaçamentos entre linhas da cultura, podem proporcionar maior eficiência na absorção de água, em função da competição das plantas nas linhas de plantio (Pholsen \& Suksri, 2007).

A eficácia de uma planta em adaptar-se a diferentes densidades populacionais irá depender do potencial genético da cultivar, onde cada variedade responde de forma diferente ao manejo empregado, de forma que, alguns genótipos têm a capacidade de comportar elevados índices produtivos em função da capacidade de exploração de recursos como: luminosidade, boa nutrição, captação de água e etc. Outra característica importante a ser levada em consideração, é a capacidade de competição da variedade, que permite a planta, elevada tolerância as altas densidades populacionais, aumentando o rendimento por área (Alvarez et al., 2006; Silva et al., 2006).

\section{Considerações Finais}

O milho (Zea mays L.) e o sorgo (Sorghum bicolor L.), são gramíneas que contribuem diretamente com a cadeia produtiva e com o agronegócio, em decorrência da sua importância nutricional em sistemas de produção animal.

As caraterísticas botânicas, morfológicas e fenológicas do milho e do sorgo, permitem que essas culturas apresentem boa produtividade e adaptabilidade em diferentes regiões do Brasil (Sul, Região Central e Nordeste).

A capacidade de adaptação do milho e do sorgo às distintas condições edafoclimáticas, dependem do potencial genético da semente e do sistema de plantio empregado, bem como, da competência do genótipo utilizado em suportar até 
certo ponto altas densidades populacionais.

Sugere-se a condução de estudos, que avaliem individualmente os atributos morfológicos e fenológicos de variedades do milho e do sorgo e suas habilidades de adaptação e produção em diferentes densidades de plantio.

\section{Agradecimentos}

Os autores agradecem à Coordenação de Aperfeiçoamento de Pessoal de Nível Superior (CAPES - Código Financeiro 001) pela bolsa de estudo.

\section{Referências}

Alvarez, C. G. D., Pinho, R. G. \& Borges, I. D. 2006. Avaliação de características agronômicas e de produção de forragens e grãos de milho em diferentes densidades de semeadura e espaçamentos entre linhas. Ciência e Agrotecnologia, 30, 402-408.

Andrade Neto, R. C., Miranda, N. O., Duda, G. P., Góes, G. B., \& Lima, A. S. (2010). Crescimento e produtividade do sorgo forrageiro BR 601 sob adubação verde. Revista Brasileira de Engenharia Agrícola e Ambiental, 14(2), 124-130.

Argenta, G., Silva, P. R. F. D., Bortolini, C. G., Forsthofer, E. L., Manjabosco, E. A., \& Beheregaray Neto, V. (2001). Resposta de híbridos simples de milho à redução do espaçamento entre linhas. Pesquisa Agropecuária Brasileira, 36(1), 71-78.

Barbano, M. T., Duarte, A. P., Brunini, O., Reco, P. C., Paterniani, M. E. A. G. Z., \& Kanthack, R. A. D. (2001). Temperatura-base e acúmulo térmico no subperíodo semeadura-florescimento masculino em cultivares de milho no Estado de São Paulo. Revista Brasileira de Agrometeorologia, 9(2), $261-268$.

Baumhardt, R. L., \& Howell, T. A. (2006). Seeding practices, cultivar maturity, and irrigation effects on simulated grain sorghum yield. Agronomy journal, 98(3), 462-470.

Bresolin, M., \& Pons, A. L. (1983). Botânica do milho. IPAGRO informa, 26, 69-72.

Coelho, A. M. (2010). A implantação da cultura do sorgo. Sistema de Produção, 2 (6a ed.). Embrapa Milho e Sorgo. ISSN 1679-012X Versão Eletrônica.

Cruz, J. C. C., Alvarenga, R. C., Novotny, E. H., Pereira Filho, I. A., Santana, D. P., Pereira, F. T. F., \& Hernani, L. C. (2008). Cultivo do milho. Sete Lagoas: Embrapa Milho e Sorgo.

Cruz, J. C., Pereira Filho, I. A., \& Gontijo Neto, M. M. (2012). Milho para silagem. Sete Lagoas: Agencia Embrapa de Informação Tecnológica. Embrapa Milho e Sorgo.

Dourado Neto, D. (1999). Modelos fitotécnicos referentes à cultura do milho. 229 f. Tese (Livre-Docência em Fitotecnia) - Escola Superior de Agricultura "Luiz de Queiroz", Universidade de São Paulo, Piracicaba.

Durães, N. N. L. Heterose em Sorgo Sacarino. (2014). 97 f. Dissertação (Mestrado em Agronomia) - Universidade Federal de Lavras. Programa de Pósgraduação em Genética e Melhoramento de Plantas, Lavras.

Empresa Brasileira de Pesquisa Agropecuária (2010). EMBRAPA Milho e Sorgo. Recuperado de https://www.embrapa.br/imprensa/noticias/2009/maio/2asemana/sorgo-sacarinodesponta-como-alternativa-promissora-na-producao-de-etanol/

Fornasieri Filho, D. (1992). A cultura do milho. Funep. 273p.

Fornasieri Filho, D. (2007). Manual da cultura do milho. Funep.

Fontes, L. A. N., \& Moura Filho, W. (1979). Calagem e adubação. Inf. Agrop, 5(56), 17-19.

Garcia, P. H. D. M. (2020). Valor nutricional da silagem de genótipos de milho e sorgo cultivados em duas densidades de semeadura. In: Nutrição e Produção Animal, (1a ed.), Org. Carlos Alexandre Oelke. Guarujá, SP: Científica Digital. p. 335- 359. ISBN:978-65-87196-42-8

Lima, L. A. R., Silva Júnior, A. B. Ferreira, P. V., Ferreira, P. V., Lira, R. C., Santos, D. F., Carvalho, A. P. V de, Teixeira, J dos S., Carvalho, D. E de., \& Cunha, J. L. X. L. (2016). Desempenho de genótipos de milho sob diferentes espaçamentos entre linhas para a produção de forragem. In: Reunião Anual Da Sociedade Brasileira Para O Progresso Da Ciência, 68, 2016, Porto Seguro. Anais... Porto Seguro: SBPC, 2016.

Magalhães, P. C., \& Durães, F. O. (2006). Fisiologia da produção de milho. Embrapa Milho e Sorgo - Circular Técnica, 76 (INFOTECA-E). 10p.

Magalhães, P. C., Durães, F. O. M., \& Rodrigues, J. A. S. (2009). Ecofisiologia do sorgo. Sistemas de Produção, 2 (5a. ed.). Sete Lagoas: Embrapa Milho e Sorgo.

Magalhães, P. C., Durães, F. O. M., Rodrigues, J. A. S (2010). Fisiologia da planta de sorgo. Sete Lagoas: Embrapa Milho e Sorgo, Comunicado técnico, 86. $4 \mathrm{p}$.

Mattoso, M. J., Garcia, L. C., Duarte, J. O., \& Cruz, J. C. 2006. Aspectos de produção e mercado do milho. Informe Agropecuário, $27,95-104$.

MAXIAGRO. Sementes e Cereais. (2010). Recuperado de http://www.maxiagrors.com.br/index.php?id=2,12,0,0,1,0 
Research, Society and Development, v. 10, n. 3, e12310313172, 2021

(CC BY 4.0) | ISSN 2525-3409 | DOI: http://dx.doi.org/10.33448/rsd-v10i3.13172

Morais, T. P. D. (2012). 82 f. Adubação nitrogenada e inoculação com Azospirillum brasilense em híbridos de milho. Dissertação (Mestrado em Agronomia) Universidade Federal de Uberlândia. Programa de Pós-graduação em Agronomia, Uberlândia.

Neumann, M., Restle, J., Filho, D. C. A., Maccari, M., Souza, A. N. M., Pellegrini, L. G., Freitas, A. K. (2005). Produção de forragem e custo de produção da pastagem de sorgo (Sorghum bicolor, L.), fertilizada com dois tipos de adubo, sob pastejo contínuo. Revista Brasileira de Agrociência, 11(2), 215-220.

Paes, M. C. D. Manipulação da composição química do milho: impacto na indústria e na saúde humana. (2008). Artigo em Hypertexto. Recuperado de http://www.infobibos.com/Artigos/2008_4/milho/index.htm

Perazzo, A. F., Santos, E. M., Pinho, R. M. A., Campos, F. S., Ramos, J. P. D. F., Aquino, M. M. D., \& Bezerra, H. F. C. (2013). Características agronômicas e eficiência do uso da chuva em cultivares de sorgo no semiárido. Ciência Rural,43(10), 1771-1776.

Pereira, A. S. et al. (2018). Metodologia da pesquisa científica. UFSM.

Pereira, O. G., Gobbi, K. F., Pereira, D. H., \& ribeiro, K. G. (2011). Conservação de forragens como opção para o manejo de pastagens. In Embrapa Caprinos e Ovinos-Artigo em anais de congresso (ALICE). In: Reunião Anual Da Sociedade Brasileira De Zootecnia, 43., 2006, João Pessoa. Produção animal em biomas tropicais: anais dos simpósios. João Pessoa: Sociedade Brasileira de Zootecnia, 2006. p. 507-539.

Pholsen, S., \& Suksri, A. (2007). Effects of phosphorus and potassium on growth, yield and fodder quality of IS 23585 forage sorghum cultivar (Sorghum bicolor L. Moench). Pakistan journal of biological sciences: PJBS, 10(10), 1604-1610.

Queiroz, L. R. (2006). 72 f. Leguminosas como fonte de nitrogênio para a cultura do milho. Tese (Doutorado em Produção Vegetal) - Universidade Estadual do Norte Fluminense Darcy Ribeiro, Centro de Ciências e Tecnologias Agropecuárias, Campos dos Goytacazes.

Ritchie, S. W., Hanway, J. J., \& Benson, G. O. (2003). Como a planta de milho se desenvolve. Piracicaba: Potafos. Informações agronômicas, 103. 20p.

Santos, F. D., Casela, C. R., \& Waquil, J. M. (2005). Melhoramento de sorgo. In BORÉM A. (org). Melhoramento de espécies cultivadas, 2 (2a ed.). (pp. 605-658). Viçosa: UFV.

Santos, G. C. L., Garcia, P. H. M., Viana, T. B. L., Borges, P. F., Araujo, L. S., \& Gonzaga Neto, S. (2020). Crescimento e eficiência do uso da água do sorgo sob distintos regimes hídricos contínuos. Archivos de zootecnia, 69(266), 164-171.

Schaffert, R. E., Rodrigues, J. A. S., Parrella, R. D. C., \& de Menezes, C. B. (2016). Síntese e melhoramento de populações de intercruzamento para aumentar recombinação genética e facilitar seleção recorrente em sorgo (Sorghum bicolor (L.) Moench). Embrapa Milho e Sorgo-Circular Técnica (INFOTECA-E).

Silva, P. D., Sangoi, L., Argenta, G., \& Strieder, M. L. (2006). Arranjo de plantas e sua importância na definição da produtividade em milho. Porto Alegre: Evangraf, 63p.

Toledo, F. D. (1980). Tecnologia das sementes. Melhoramento e produção do milho. Campinas: Fundação Cargill, $571-619$.

Viola, E. A. (1980). Considerações sobre a cultura do milho. Instituto de Pesquisa Agronômica. IPAGRO, Porto Alegre, 23, 3-8. 